\title{
Erratum to: Are the motor features of verb meanings represented in the precentral motor cortices? Yes, but within the context of a flexible, multilevel architecture for conceptual knowledge
}

David Kemmerer ${ }^{1,2}$

Published online: 9 June 2016

(C) Psychonomic Society, Inc. 2016

Erratum to: Psychon Bull Rev

DOI 10.3758/s13423-014-0784-1

This article should have been included in this special issue of Psychonomic Bulletin \& Review, but was inadvertently published in an earlier issue. You can find the text of the article at the link below.

The online version of the original article can be found at http://dx.doi.org/ 10.3758/s13423-014-0784-1.

David Kemmerer

kemmerer@purdue.edu

1 Department of Speech, Language, and Hearing Sciences, Lyles-Porter Hall, Purdue University, 715 Clinic Drive, West Lafayette, IN 47907, USA

2 Department of Psychological Sciences, Purdue University, West Lafayette, IN, USA 